\title{
Construcionalização e competição de conectores concessivos e concessivo-condicionais instanciados pelo esquema [Xque] em português
}

\author{
Constructionalization and competition of concessive and \\ concessive-conditional connectors instantiated by the scheme \\ [Xque] in Portuguese
}

\author{
Thiago dos Santos Silva* \\ thiagoletrasufri@hotmail.com \\ Universidade Federal do Rio de Janeiro \\ Maria Maura Cezario ${ }^{\star *}$ \\ mmcezario@gmail.com \\ Universidade Federal do Rio de Janeiro
}

\begin{abstract}
RESUMO: Este artigo tem como objetivo investigar a formação dos conectores ainda que e mesmo que, instanciados pelo esquema [Xque] ConECT em português, assim como analisar seus usos e contextos em que poderiam estar em competição. Foram coletados dados do Corpus do Português, do século XIII ao século XX, a fim de observar os processos de mudanças pelos quais passaram as construções analisadas, bem como propor a rede linguística da qual as construções fazem parte. A pesquisa está inserida numa abordagem construcional de mudança linguística (TRAUGOTT; TROUSDALE, 2013), sob a ótica da Linguística Funcional Centrada no Uso. Os dados nos mostram que os conectores analisados passaram por um processo de construcionalização, visto que houve mudanças na forma e na função, formando novas construções na língua. Mostram também que, embora sejam semanticamente semelhantes, esses conectores tendem a ser usados em contextos pragmático-discursivos diferentes.
\end{abstract}

PALAVRAS-CHAVE: Construcionalização. Mudança linguística. Conectores.

ABSTRACT: This article aims to investigate the formation of the connectors ainda que and mesmo que - both with the meaning even though - instantiated by the [Xque] schema in Portuguese, as well as to verify their uses in contexts in which they could be in competition. Data were collected from the Corpus of Portuguese, from the 13th to the 20th century, in order to observe the processes of change through which the analyzed items were passed, as well as to propose the linguistic network of which the constructions are part of. The research follows a constructional approach to linguistic change (TRAUGOTT; TROUSDALE, 2013) from the perspective of The Usage-Based Linguistics. The data show that the analyzed connectors underwent a

\footnotetext{
Doutorando em Linguística pelo Programa de Pós-graduação em Linguística da Universidade Federal do Rio de Janeiro; bolsista do CNPq.

Professora Titular de Linguística da Faculdade de Letras e do Programa de Pós-graduação em Linguística da Universidade Federal do Rio de Janeiro; Bolsista de Produtividade do CNPq.
} 
process of constructionalization, since there were changes in the form and in the function, creating new constructions in the language. They also show that, although semantically similar, these connectors tend to be used in different pragmaticdiscursive contexts.

KEYWORDS: Constructionalization. Linguistic change. Connectors.

\section{Introdução}

Esta pesquisa tem como principal objetivo apresentar uma análise acerca da formação das construções ainda que e mesmo que ao longo da história do português, a partir da perspectiva teórica da Linguística Funcional Centrada no Uso e do modelo construcional de mudança linguística abordado por Traugott e Trousdale (2013). Também apresenta uma análise de fatores que demonstram que as orações com ainda que e mesmo que, embora semanticamente muito semelhantes, não são empregadas nos mesmos contextos discursivo-pragmáticos.

Os dados analisados foram retirados do Corpus do Português, com o objetivo de verificar as ocorrências das construções a partir do século XIII. Nesta análise, pretendemos explorar os diferentes contextos pragmáticos nos quais as construções são utilizadas e demonstrar como a posição da oração influencia no conteúdo semântico-pragmático veiculado.

Entendemos que as construções apresentadas neste trabalho veiculam ideias contrastivas, assim, buscamos analisar quais tipos de relações são instauradas pelas duas construções, a partir das subcategorizações feitas por König (1985a) e Neves (2000) sobre as orações concessivas. No que diz respeito aos conectores concessivos em português, encontramos estudos importantes sobre o tema e que serviram de base para esta pesquisa nos trabalhos de Neves (2000), Salgado (2007), Felício (2008), Garcia (2010), Rosário (2012) e Fontes (2016).

Ao analisar as orações concessivas no português, Neves (2000) propõe a seguinte subcategorização ${ }^{1}$ sobre as relações instauradas por elas: as que possuem caráter factual, que são chamadas de concessivas (CC), e as de caráter eventual, que são denominadas condicionais-concessivas (CD). Para entender como é o comportamento das concessivas, a autora enfatiza que, nestas orações, tanto o

\footnotetext{
${ }^{1}$ Em Neves (2000) encontramos também a subcategoria "concessiva contrafactual/real". Neste caso, tanto a oração concessiva quanto a subordinada devem ser não-verdadeiras para que a asserção global seja também não verdadeira. Sendo assim, a enunciação de uma contrafactual implicita a nãorealização dos conteúdos presentes na subordinada e na principal: mesmo que pudesse querer, a vaca não poderia sorrir nem chorar (exemplo retirado de NEVES, 2000).
} 
conteúdo proposicional expresso pela oração principal e pela oração concessiva são verdadeiros. Vejamos o seguinte exemplo apresentado pela autora:

(1) contei também o número de estudantes ... quarenta e um ... e: eu tenho quase certeza, embora não tenhamos a lista (NEVES, 1999, p. 549).

Em (1), é possível notar que tanto o conteúdo da oração principal quanto o da subordinada são verdadeiros, ou seja, possui caráter factual, concessivo.

Por outro lado, nas de caráter eventual, chamadas de condicionalconcessivas, apenas o conteúdo da oração principal é verdadeiro, já o da subordinada é hipotético, podendo ser verdadeiro ou falso. Vejamos mais um exemplo apresentado pela autora:

(2) nós temos as reuniões ... muito mais participação, porque, mesmo que alguns professores faltem porque tenham outros ... outros afazeres no ambulatório, mas sempre tem um bom número de reuniões (NEVES, 1999, p. 548).

Em (2), é possível notar que o conteúdo proposicional expresso pela oração subordinada é hipotético, dando margem à possibilidade ou não de que ocorra.

Estudos feitos por König (1985a) mostram que os conectores concessivos são formados a partir de construções já disponíveis na língua. De acordo com o autor, a maneira como se deu a formação destes conectores seria semelhante em muitas línguas. Para sintetizar, ele propõe alguns grupos que teriam feito parte da história de conectores concessivos: quantificadores, partículas focais e enfáticas, conjunções temporais e condicionais, itens que expressam noção de conflito e itens que expressam coexistência entre dois eventos.

Ainda de acordo com König (1985b), as concessivo-condicionais teriam sido formadas por quantificadores e partículas focais ou enfáticas. Para ele, o estágio concessivo-condicional serviu de origem para a formação dos conectores concessivos, visto que há algumas similaridades envolvendo estes dois tipos de conectores.

Os objetivos específicos propostos para este trabalho são:

(a) analisar a trajetória da formação histórica de ainda que e mesmo que, bem como os processos cognitivos envolvidos no surgimento das construções;

(b) identificar se as construções primeiro passaram por um valor concessivocondicional até chegar ao valor concessivo; 
(c) observar a posição (anteposta ou posposta) das orações introduzidas por mesmo que e ainda que, a partir de seus usos semânticos e seus papéis pragmáticos.

Sendo assim, as hipóteses que levantamos para os nossos objetivos específicos são:

(a') as construções teriam passado por processos como analogia e chunking, além de terem seus usos fortalecidos por contextos de ordem discursivo-funcional e semântico-pragmático;

(b') assim como mostram os estudos de König (1985) sobre a história dos conectores concessivos em inglês, o valor concessivo-condicional seria um estágio intermediário destes conectores na língua portuguesa até chegarem ao valor concessivo;

(c') haveria relação entre posições das orações hipotáticas com ainda que e mesmo que e papel semântico-discursivo-pragmático.

Este trabalho está organizado da seguinte maneira: primeiro apresentamos os pressupostos teóricos que norteiam este trabalho, bem como o modelo de mudança linguística adotado; depois apresentamos a visão funcionalista sobre o encaixamento de orações, seguida da metodologia adotada, análise dos dados e, por fim, as conclusões as quais conseguimos chegar.

\section{Linguística Funcional Centrada no Uso}

A Linguística Funcional Centrada no Uso (LFCU) parte do princípio de que a estrutura da língua emerge à medida que esta é usada e que a gramática é vista como uma estrutura que está em constante mudança. Este modelo propõe que, se desejamos entender o funcionamento da linguagem humana, os aspectos cognitivos e comunicativos que atuam no uso da língua não podem estar de fora da análise linguística. A gramática de uma língua é moldada a partir de seu uso concreto, pois é no contexto real de comunicação que o falante faz adaptações a fim de atingir seus objetivos comunicativos.

Em relação à metodologia, o modelo baseado no uso utiliza dados linguísticos reais para descrever a teoria, porque defende a ideia de que a estrutura das línguas está ligada aos seus usos. Outro fator importante para o modelo é a frequência de 
uso, visto que é possível que, pela alta frequência de um determinado item, surja um novo padrão na língua. Nesse sentido, Bybee (2003) apresenta dois métodos para analisar a frequência de uma determinada construção: frequência type e frequência token. A frequência type (frequência de tipo) diz respeito a um padrão específico e pode ser observada identificando diferentes itens lexicais com os quais uma determinada construção pode ser usada. A frequência token (frequência de ocorrência) é o número de ocorrências do item no texto, ou seja, a frequência dos construtos. Sendo assim, de acordo com a autora, a frequência é um fator colaborador primário para o processo de mudança.

\subsection{Processos cognitivos de domínio geral}

Como a atuação da cognição humana possui grande importância no processo de mudança linguística, ao tratarmos dos processos cognitivos de domínio geral, não nos referimos apenas aos processos específicos à língua, mas também situamos a língua num amplo contexto do comportamento humano. Sendo assim, os processos que atuam na língua atuam em outros domínios da cognição humana.

Bybee (2010) apresenta cinco mecanismos cognitivos básicos do domínio geral que moldam a estrutura e o conhecimento da linguagem. Em oposição à visão da linguística formal, a autora postula que a linguagem é fruto de processos cognitivos do domínio geral, dentre eles estão: a categorização, o chunking, a analogia, memória rica e associação transmodal.

A categorização tem relação com a capacidade de reconhecer padrões. $O$ chunking (encadeamento) é processo pelo qual sequência de itens que são frequentemente usados juntos formam uma unidade mais complexa (um único bloco cognitivo). A memória rica está relacionada com a capacidade de estocagem mental dos detalhes da experiência com o uso linguístico, incluindo detalhes fonéticos para palavras e sintagmas, contextos de uso, significados e inferências associados aos enunciados. Cada experiência com a língua tem um impacto nas representações cognitivas. A analogia é a capacidade do falante de produzir novas enunciações com base em outros enunciados já produzidos em experiências discursivas anteriores. A associação transmodal tem a ver com o fato de que as experiências coocorrentes tendem a ser cognitivamente associadas. Tal associação fornece um link entre significado e forma. 
Tomasello (2003) apresenta dois grandes grupos de capacidades cognitivas do domínio geral: a capacidade de ver o outro como ser intencional e mental e a capacidade de busca de padrão. Neste último, estão incluídas basicamente a capacidade de categorizar e a de fazer analogias. De acordo com o autor, no processo de aquisição de linguagem sempre é preciso levar em consideração os eventos e os estados de coisas nele envolvidos.

\section{2 Construcionalização e mudança construcional}

De acordo com Traugott (1995), a construção gramatical é o pareamento convencionalizado de forma e sentido, visto como um esquema simbólico, a partir do qual se instanciam os componentes da gramática. De acordo com Goldberg (2013: 219), todo nosso conhecimento acerca da linguagem é capturado por uma rede de construções, sendo assim, a língua é uma rede de relações entre as construções.

Traugott e Trousdale (2013) sintetizam a hierarquia construcional a fim de explicitar os níveis esquemáticos de uma construção, envolvendo desde graus mais específicos a esquemas mais abstratos. De acordo com os autores, o nível mais alto seria o esquema, com um alto grau de abstração; o subesquema estaria no nível intermediário, sendo uma subcategoria do esquema maior; a microconstrução seria o uso individual da construção no nível do pareamento específico, já o construto se refere à ocorrência da construção no uso linguístico.

Para os autores, a língua é uma rede de relações entre as construções, sendo assim, as mudanças estariam interconectadas e o papel do linguista é mostrar como a rede se reestrutura face essas mudanças. Uma construção como ainda que, por exemplo, seria uma instanciação de uma construção mais abstrata, ou seja, num nível mais alto na rede linguística, que serviria de modelo para o surgimento de outras construções na língua provenientes do mesmo esquema.

Traugott e Trousdale (2013) apresentam dois tipos de mudanças linguísticas: a) Mudanças construcionais (constructional changes) - mudanças que afetam uma construção existente. As mudanças são no plano da forma ou do conteúdo. A mudança construcional é a mudança que afeta a dimensão interna da construção, não envolvendo a criação de um novo nó.

b) Construcionalização (constructionalization) - é a criação de um pareamento simbólico de forma e função, ou seja, a criação de um novo signo (o que representa 
um novo nó na rede linguística). É quando ocorrem mudanças na forma e no conteúdo.

Em outras palavras, o processo de construcionalização tem a ver com a criação de um pareamento de uma nova forma com um novo significado. Se pensarmos no campo pragmático, esse processo se dá por meio de neoanálises e analogias feitas pelo falante, passando também pelo campo semântico e, por último, pelo campo formal.

\section{Encaixamento de orações: a visão funcionalista}

Dada a mistura de critérios presente nas abordagens tradicionais, buscamos nos estudos linguísticos uma melhor maneira de caracterizar as orações adverbiais (principalmente as concessivas iniciadas por ainda que e mesmo que). De acordo com Hopper e Traugott (1993), há um continuum relacionado às orações complexas baseado nos critérios dependência e encaixamento, que seriam agrupadas em: paratáticas, hipotáticas e subordinadas:

Figura 1: Continuum entre as orações

\begin{tabular}{|lllll|}
\hline parataxe & $>$ & hipotaxe & $>$ & subordinação \\
- encaixamento & & - encaixamento & & + encaixamento \\
- dependência & & + dependência & & + dependência \\
\hline
\end{tabular}

Fonte: Adaptado de Hopper e Traugott (1993, p. 170)

A parataxe, de acordo com os autores, é menos integrada que a hipotaxe e possui uma relação de independência relativa entre os núcleos que compõem o complexo oracional. Em outras palavras, a parataxe abrange tanto a justaposição (desde que sob um mesmo contorno entoacional) e a coordenação (quando há um elemento que sinalize a relação entre as orações). A hipotaxe abarca orações em que há um núcleo e uma ou mais margens apresentam dependência relativa, não estão totalmente inclusas em nenhum constituinte da oração núcleo, completando assim a estrutura argumental do verbo (orações apositivas e adverbiais da abordagem tradicional). Por outro lado, a subordinação abarca orações que possuem dependência completa, estabelecendo grau máximo de integração entre margem e núcleo.

Como abordado por Gonçalves et al.: 
a integração sintática entre duas orações é explicada pelo subprincípio da proximidade, que, direcionado para os processos de combinação de sentenças, estipula que tal integração decorreria de uma vinculação semântica entre os dois eventos codificados pelas orações articuladas (2007, p. 134).

Entendemos que os tipos de orações que são iniciadas pelos conectores que estudamos são do tipo hipotáticas, pois o tipo de conector que une a hipotática com a oração núcleo tem, geralmente, sua origem em um nome, verbo, advérbio, pronome, etc, além disso, as orações hipotáticas concessivas que constituem margens estabelecem relação semântica com a oração núcleo, podendo considerar o critério dependência, entretanto, como mostram Hopper e Traugott (1993), pode ser que às vezes apresentem uma relação mais frouxa com a oração núcleo, sendo não encaixadas.

\section{Procedimentos metodológicos}

Neste trabalho, fazemos uso dos dados coletados do Corpus do Português, uma plataforma online que reúne diversos textos em vários dialetos da língua portuguesa. No site, encontramos 4 subtipos de corpus, e nesta pesquisa fazemos uso do denominado Gênero/Histórico, que reúne dados do século XIII ao século XX e possui mais de 45 milhões de palavras, dividido em várias subseções, incluindo fala e escrita. Entretanto, em nossa análise, verificamos apenas as ocorrências na modalidade escrita.

Dividimos a coleta dos dados em duas etapas: a primeira começa no século $X I I I$ e vai até o século XV, e a segunda vai do século XVIII ao século XX. Isso porque nos séculos XVI e XVII não havia ocorrência da forma mesmo que, o que impossibilita a comparação com a forma ainda que neste período da história da língua.

Coletamos 150 dados na segunda etapa, porém nos séculos iniciais as ocorrências das construções foram menores do que o número estipulado de coleta previsto. Sendo assim, de maneira que a pouca quantidade encontrada não enviesasse os dados encontrados, procuramos manter um equilíbrio considerando a média do número de palavras que compunham o corpus por século.

Analisamos os dados segundo os seguintes fatores: 
(a) semântica da oração hipotática, verificando se os usos possuíam a ideia concessiva ou concessivo-condicional;

(b) frequência de ocorrência das orações em estudo ao longo dos séculos;

(c) posição da oração hipotática com ainda que e mesmo que em relação à oração matriz;

(d) status informacional da oração hipotática.

\section{História e usos de orações hipotáticas com ainda que e mesmo que 41 Formação dos conectores}

Nesta seção, apresentamos os resultados encontrados em nossa pesquisa após análise dos dados, levanto em consideração os fatores apresentados na seção anterior.

Encontramos, como mostra o exemplo 3, a forma ainda que com sentido contrastivo nos séculos iniciais da pesquisa (séc. XIII ao séc. XV) o que sugere, como mostram os estudos de Barreto (1999), que a forma já era empregada com esse sentido em séculos anteriores.

(3) E seram atam sotíís que entrarã nas casas, ainda que as portas estem çarradas

L. (Vidas de Santos de um Manuscrito Alcobacense,1200 - 1300)

No exemplo 3, nota-se que o sentido contrastivo já está presente e que ainda que já é usado como um conector. Entretanto, assim como no português atual, usos de ainda como partícula focal aditiva (cf. König, 1991) seguida do conector que também já aparecem nos dados a partir do século XIII.

(4) vierõ dizëdo ainda / que virom visom de anjos quedizem que viue. \& (Euangelhos e epistolas con suas exposições en romãce, 1497)

No exemplo 4, ainda partícula focal aditiva está terminando uma oração e o complementizador que iniciando a oração seguinte. Pensamos que este contexto tenha influenciado na formação de ainda que conector contrastivo, como representado na figura 2 , a seguir: 
Figura 2: Processo de formação de ainda que contrastivo

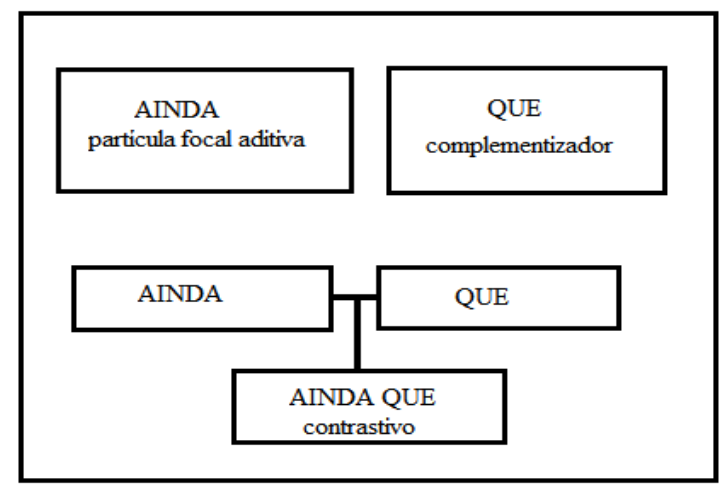

Fonte: Santos Silva (2019)

Traugott e Trousdale (2013) apresentam alguns micropassos que antecedem uma mudança linguística. De acordo com os autores, a mudança começa com microinovações no nível do construto, ou seja, no uso linguístico, porém, só é considerada mudança quando há a convencionalização da microconstrução entre os usuários da língua. Os autores apresentam, então, os seguintes micropassos que atuam neste processo:

$1^{\circ}$ Inovação: nesta etapa, o ouvinte interpreta e analisa o construto de uma maneira diferente daquela expressada pelo falante;

$2^{\circ}$ Convencionalização: o ouvinte que reanalisou o construto de uma maneira diferente, começa a utilizar o construto com o novo significado ou em diferentes contextos;

$3^{\circ}$ Construcionalização: há a criação de uma nova microconstrução na rede, após a neoanálise semântica e morfossintática ser convencionalizada pelos falantes;

$4^{0}$ Pós construcionalização: há a possibilidade da nova microconstrução expandir, causando uma reestruturação da rede linguística;

$5^{\circ}$ Redução de forma: há uma redução de uso que pode chegar a zero ocasionada pelo frequente uso do token.

Pensamos que os contextos que favoreceram o uso de ainda que como conjunção contrastiva foram os contextos nos quais os sentidos hipotético, causal e condicional estavam presentes na situação comunicativa.

No século XIII, já foi possível encontrar contextos nos quais a forma ainda estava numa oração e a forma que na oração seguinte. Nossa hipótese, baseada na formação de outros conectores (cf. SANTOS; CEZARIO, 2017) que, pela repetição do adverbial neste contexto de uso, houve uma reinterpretação das formas, e os 
elementos passaram pelo processo cognitivo denominado chunking, que é quando dois ou mais itens são vistos como um único bloco cognitivo, formando assim a conjunção ainda que.

Pensamos que mesmo que tenha passado por um processo semelhante. A forma começa a ser encontrada com mais frequência no século XVIII, sendo encontrada apenas o item mesmo - partícula enfática ou equivalente a 'igual' - junto ao que nos séculos anteriores, como mostra o exemplo abaixo:

(5) Ant. Nam erão certo melhores que ss Phariseus, antes seguião opiniões, \& documentos muyto piores: porque segundo se refere nos Actos dos Apostolos, negavão a Resurreyçam dos mortos; \& aver Anjos, \& espiritos: cousas que os Phariseus confessavam. Josepho diz delles cousas mais feas. Affirmavam que as almas juntamente, \& no mesmo tempo acabavam com os corpos, \& nas mais cousas sentião o mesmo / que os Samaritanos, excepto que vivendo em Hierusalem sacrificavam como os mesmos Judeus. (Amador Arrais, 1589).

Entretanto, alguns dados parecem deixar uma certa ambiguidade na interpretação do item, ou seja, alguns contextos que podem ser considerados como críticos, que serviram de gatilho para a formação da construção com sentido contrastivo. Vejamos o seguinte exemplo encontrado no século XV que, ao nosso ver, é ambíguo e possível gatilho para a construcionalização do item:

(6) A esto Respondemos que nos praz por vos fazer merçe que nos praz que acabado o tempo do contrauto da cortiça ho nam aJa hy mais $E$ assy mesmo que se nom ffaça trauto de coiros, Jtem Outrossy ao que pedijs que pello dano que nosso pouoo Reçebe de sse arremdarem as chamçelarias das Correições o que Ja muytas vezes foy defesso per Nossos amteçessores, (Cortes portuguesas, 1498).

No exemplo (6), mesmo aparece seguido de itens que, normalmente, acompanham a forma como o sentido da partícula enfática: assim mesmo. Além disso, observamos que o verbo que segue a forma mesmo está no modo subjuntivo, modo comumente encontrado com a forma mesmo que contrastiva, o que sugere um certo grau de condição e concessão presente na situação comunicativa.

Outro ponto é o fato de alguns contextos com o uso da construção em (6) explorarem a negação, sendo este domínio bem próximo do domínio de contraste. Pensando na formação da construção, postulamos o seguinte esquema: 
Figura 3: Processo de formação de mesmo que contrastivo

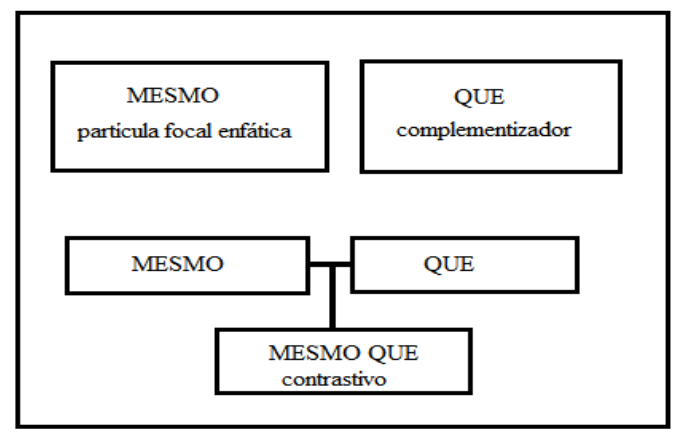

Fonte: Santos Silva (2019)

Como representado na Figura 3, mesmo apareceria com o sentido de partícula enfática ou com o sentido de 'igual' ao lado de que. Pensamos que, como já existia um esquema [Xque] na língua, realizado no nível do construto pela forma ainda que contrastiva, o falante, por analogia a esta forma já existente, recrutou o item mesmo para o slot $\mathrm{X}$ da construção.

Os fatores que teriam contribuído para escolha do item seriam o fato de mesmo, assim como ainda ser uma partícula focal, a pressão do contexto comunicativo, podendo apresentar uma ideia de condição e/ou consequência e a interpretação de mesmo que como um único bloco cognitivo, pela repetição do item.

\section{Construções hipótaticas com ainda que e mesmo que: análise de propriedades da função e da forma}

\section{Tipo de conector e função contrastiva}

Neves (2000) faz uma subcategorização das concessivas em português, como apresentado na introdução deste trabalho. A autora apresenta alguns comportamentos das orações concessivas: concessivas (CC) e concessivocondicionais (CD).

Nesta primeira parte da análise, apresentamos apenas os resultados de ainda que, pois foi o único conector encontrado durante a primeira fase escolhida para pesquisa, ou seja, do século XIII até o século XV. Organizamos os resultados na tabela 1: 
Tabela 1: Tipo de conector e função contrastiva século XIII ao XV

\begin{tabular}{|c|c|c|c|c|c|c|c|c|}
\hline $\begin{array}{c}\text { Conector e } \\
\text { função } \\
\text { contrastiva }\end{array}$ & \multicolumn{2}{|c|}{ Século XIII } & \multicolumn{2}{|c|}{ Século XIV } & \multicolumn{2}{c|}{ Século XV } & \multicolumn{2}{c|}{ TOTAL } \\
\cline { 2 - 9 } & CD & CC & CD & CC & CD & CC & CD & CC \\
\hline AINDA & $5 / 8$ & $3 / 8$ & $20 / 48$ & $28 / 48$ & $58 / 150$ & $92 / 150$ & $\mathbf{8 3 / 2 0 6}$ & $\mathbf{1 2 3 / 2 0 6}$ \\
QUE & $\mathbf{6 3 \%}$ & $\mathbf{3 7 \%}$ & $\mathbf{4 2 \%}$ & $\mathbf{5 8 \%}$ & $\mathbf{3 8 \%}$ & $\mathbf{6 2 \%}$ & $\mathbf{4 0 \%}$ & $\mathbf{6 0 \%}$ \\
\hline
\end{tabular}

Com base nos resultados apresentados na Tabela 1, dos 206 dados encontrados entre o século XIII e o século XV, 83 ocorrências foram de construções concessivo-condicionais (CD), o que representa $40 \%$ dos dados, e 123 foram de concessivas (CC), totalizando $60 \%$ dos dados.

Observamos que, dos 8 dados encontrados no século XIII, 5 deles apresentavam o sentido concessivo-condicional (exemplo 7), representando 63\% dos dados, e 3 apresentavam o sentido concessivo (exemplo 8), representando $37 \%$.

(7) Mas, como fez este bem, ainda que fezesse cem tanto melhor, eu nõ lhe darya seu padre. (Crónica Geral de Espanha de 1344)

(8) Amigos e vassallos, bem vejo o que me dizedes. queroo fazer muy de grado, ainda que mayor cousa é. (Crónica Geral de Espanha de 1344)

No exemplo (7), a oração subordinada possui um caráter mais hipotético, podendo ser verdadeiro ou falso, enquanto na oração 8 , a subordinada possui uma proposição verdadeira.

Após análise dos dados, notamos que no século XIII, há predomínio de usos com sentido concessivo-condicional, nos séculos XIV e XV, porém, há aumento do sentido concessivo e diminuição de concessivo-condicional.

$\mathrm{Na}$ Tabela 2, apresentamos os resultados encontrados referente ao período que vai do século XVIII ao século XX e em competição com mesmo que (usado nos textos a partir do século XVIII):

Tabela 2: Tipo de conector e função contrastiva século XVIII ao XX

\begin{tabular}{|c|c|c|c|c|c|c|c|c|}
\hline $\begin{array}{c}\text { Conector e } \\
\text { função } \\
\text { contrastiva }\end{array}$ & \multicolumn{2}{|c|}{ Século XVIII } & \multicolumn{2}{|c|}{ Século XIX } & \multicolumn{2}{|c|}{ Século XX } & \multicolumn{2}{|c|}{ TOTAL } \\
\cline { 2 - 9 } & $\mathrm{CD}$ & $\mathrm{CC}$ & $\mathrm{CD}$ & $\mathrm{CC}$ & $\mathrm{CD}$ & $\mathrm{CC}$ & CD & CC \\
\hline AINDA & $63 / 150$ & $87 / 150$ & $54 / 150$ & $96 / 150$ & $67 / 150$ & $83 / 150$ & $\mathbf{1 8 4 / 4 5 0}$ & $\mathbf{2 6 6 / 4 5 0}$ \\
QUE & $\mathbf{4 2 \%}$ & $\mathbf{5 8 \%}$ & $\mathbf{3 6 \%}$ & $\mathbf{6 4 \%}$ & $\mathbf{4 4 \%}$ & $\mathbf{5 6 \%}$ & $\mathbf{4 0 \%}$ & $\mathbf{6 0 \%}$ \\
\hline MESMO & $1 / 1$ & $0 / 1$ & $19 / 23$ & $4 / 23$ & $98 / 150$ & $52 / 150$ & $\mathbf{1 1 8} / \mathbf{1 7 4}$ & $\mathbf{5 6 / 1 7 4}$ \\
QUE & $\mathbf{1 0 0 \%}$ & $\mathbf{0 \%}$ & $\mathbf{8 2 \%}$ & $\mathbf{1 8 \%}$ & $\mathbf{6 5 \%}$ & $\mathbf{3 5 \%}$ & $\mathbf{6 7 \%}$ & $\mathbf{3 3 \%}$ \\
\hline
\end{tabular}


A partir dos resultados encontrados na Tabela 2, das 150 ocorrências de ainda que no século XVIII, 63 foram de concessivas-condicionais, $42 \%$ dos dados, e 87 com valor concessivo, representando $58 \%$ dos dados. No século XIX, encontramos 54 ocorrências do item com valor concessivo-condicional e 96 ocorrências com o valor concessivo, representando $36 \%$ e $64 \%$ dos dados, respectivamente. Por fim, no século XX, dos 150 dados analisados, 67 expressavam a ideia concessivo-condicional, $44 \%$ dos dados, e 83 denotavam ideia concessiva, representando $56 \%$ dos dados encontrados. Dos 450 dados analisados da forma ainda que, 184 foram ocorrências de valor concessivo-condicional e 266 ocorrências de valor concessivo.

A partir desses resultados, vemos que há uma tendência de ainda que expressar mais a ideia concessiva, embora seu uso como condicional-concessivo ocorra nos três séculos.

Já a forma mesmo que totalizou 174 ocorrências, somando os três séculos, sendo 118 com o valor concessivo-condicional (exemplo 7), 60\% dos dados e 56 com o valor concessivo, $40 \%$ dos dados. No século XVIII, encontramos 1 dado do item apenas como concessivo-condicional. No século XIX, das 23 ocorrências de mesmo que, 19 apresentaram ideia concessivo-condicional, $82 \%$ dos dados, e 4 concessivas, representando $18 \%$ dos dados. Por fim, no século XX, das 150 ocorrências da construção, 98 foram com sentido condicional-concessivo e 52 com o sentido concessivo, representando $65 \%$ e $35 \%$, respectivamente.

(9) mesmo que ele quisesse ser eleito, ele não alcançaria (1790)

Em (9), a oração subordinada possui uma proposição hipotética, com possibilidade de ser verdadeira ou falsa. Em todos os séculos, o uso do conector com valor concessivo-condicional foi superior ao uso do mesmo conector com valor concessivo. Assim, é possível que mesmo que apresente mais uso com valor concessivo-condicional que a forma ainda que.

Com base nos resultados encontrados, ainda que segue tendo seu uso predominante como concessivo, mas mesmo que apresenta uma tendência diferente. Seu primeiro uso é como concessivo-condicional e, pelos resultados encontrados, segue até hoje com predominância para este uso. 


\section{Relação entre posição das orações hipotáticas com ainda que e mesmo que e seus papéis semânticos e pragmáticos.}

Nas Tabelas 3, 4 e 5 apresentamos a posição das orações hipotáticas e as ideias que veiculam do século XVIII ao século XX (séculos em que já é possível comparar os dois itens):

Tabela 3: Posição da oração com ainda que e mesmo que no século XVIII

\begin{tabular}{|c|c|c|c|c|}
\hline \multirow{3}{*}{$\begin{array}{l}\text { Con ector, } \\
\text { posição } \\
\text { semântica }\end{array}$} & \multicolumn{4}{|c|}{ Século XVIII } \\
\hline & \multicolumn{2}{|c|}{ AINDA QUE } & \multicolumn{2}{|c|}{ MESMO QUE } \\
\hline & Anteposta & Posposta & Anteposta & Posposta \\
\hline CD & $22 / 63=34 \%$ & $41 / 63=66 \%$ & $1 / 1=100 \%$ & $0 / 1=0 \%$ \\
\hline $\mathrm{CC}$ & $39 / 87=44 \%$ & $48 / 87=56 \%$ & $0 / 0=0 \%$ & $0 / 0=0 \%$ \\
\hline TOTAL: & $61 / 150=40 \%$ & $89 / 150=60 \%$ & $1 / 1=100 \%$ & $0 / 1=0 \%$ \\
\hline
\end{tabular}

Tabela 4: Posição da oração com ainda que e mesmo que no século XIX

\begin{tabular}{|c|c|c|c|c|}
\hline \multirow{3}{*}{$\begin{array}{l}\text { Conector, } \\
\text { posição } \\
\text { semântica }\end{array}$} & \multicolumn{4}{|c|}{ Século XIX } \\
\hline & \multicolumn{2}{|c|}{ AINDA QUE } & \multicolumn{2}{|c|}{ MESMO QUE } \\
\hline & Anteposta & Posposta & Anteposta & Posposta \\
\hline CD & $16 / 54=30 \%$ & $38 / 54=70 \%$ & $11 / 19=58 \%$ & $8 / 19=42 \%$ \\
\hline $\mathrm{CC}$ & $35 / 96=37 \%$ & $61 / 96=63 \%$ & $2 / 4=50 \%$ & $2 / 4=50 \%$ \\
\hline TOTAL: & $51 / 150=34 \%$ & $99 / 150=66 \%$ & $13 / 23=57 \%$ & $10 / 23=43 \%$ \\
\hline
\end{tabular}

Tabela 5: Posição da oração com ainda que e mesmo que no século XX

\begin{tabular}{|l|c|c|c|c|}
\hline \multirow{2}{*}{$\begin{array}{l}\text { Conector, } \\
\text { posição } \\
\text { semântica }\end{array}$} & \multicolumn{4}{|c|}{ Século XX } \\
\cline { 2 - 5 } & \multicolumn{2}{|c|}{ AINDA QUE } & \multicolumn{2}{c|}{ MESMO QUE } \\
\cline { 2 - 5 } CD & Anteposta & Posposta & Anteposta & Posposta \\
\hline CC & $26 / 67=39 \%$ & $41 / 67=61 \%$ & $69 / 98=70 \%$ & $29 / 98=30 \%$ \\
\hline TOTAL: & $31 / 83=38 \%$ & $52 / 83=62 \%$ & $31 / 52=60 \%$ & $21 / 52=40 \%$ \\
\hline
\end{tabular}

A partir dos dados apresentados nas tabelas acima, vemos que do século XVIII ao século $\mathrm{XX}$, ainda que possui uso predominante na posição posposta, enquanto mesmo que possui uso predominante na posição anteposta.

Orações hipotáticas, de acordo com a literatura funcionalista (Cf. GIVÓN, 1990, HALLIDAY, 2004; ANTONIO, 2004), tendem a ocorrer após a matriz quando apresentam informações novas, ou seja, quando são focais (nos termos de Lambrecht, 1994). Sendo assim, verificamos a relação entre informação focal e 
informação não-focal com relação aos dados analisados. Para este fator, analisamos apenas os dados do século XX. Os resultados revelam a maioria das orações com ainda que são focais, como no dado abaixo, e, portanto, tendem a ser colocadas em posição posterior à oração principal $(66 \%$ dos dados do século $\mathrm{XX})$, como no exemplo abaixo:

(10) Segundo Cecília, para melhorar a qualidade de vida, apesar de todos os contratempos, é necessário aprender a dar atenção e carinho a si mesmo, diariamente. Ela sugere, por exemplo, que a pessoa fixe o olhar, por alguns minutos, num ponto e tente não pensar em absolutamente nada - ainda que esteja dentro de um vagão do metrô lotado. (CORPUS DO PORTUGUÊS, século XX)

A oração com ainda que apresenta uma informação focal, que chama a atenção do leitor exatamente por se apresentar totalmente nova em relação ao discurso precedente.

Já as orações com mesmo que tendem a ser tópicas, reforçando alguma informação já dada, e são embaladas de forma a ficarem na posição anteposta à principal ( $62 \%$ dos dados do português do século XX), como no exemplo a seguir:

(11) Os trabalhadores são reféns da entidade sindical e não a entidade sindical é instrumento dos trabalhadores, porque o sindicato pode negociar em nome da categoria e pode assinar acordo sem convocar assembléia. Mesmo que o acordo assinado traga prejuízo aos trabalhadores, vale como força de lei. Isso precisa ser revertido. (CORPUS DO PORTUGUÊS, século XX)

A oração com mesmo que traz parte da informação tópico - o acordo assinado- que já estava em cena no discurso antecedente. A informação de que esse acordo vale como força de lei é o foco do período e está dada na informação matriz.

Nossa pesquisa demonstra uma diferença relevante em relação aos usos de construções com ainda que e mesmo que. Embora pareçam sinônimas, elas são pragmaticamente diferentes e a apresentam estatutos informacionais diferentes. As orações com ainda que tendem a ser concessivas propriamente ditas e a ser focais. As orações com mesmo que tendem a ser concessivo-condicionais e tendem a apresentar informação velha, tópica.

Croft (2001) exemplifica a partir de uma estrutura simbólica construcional como se daria o pareamento entre forma (propriedades sintáticas, morfológicas e fonológicas) e significado (propriedades semânticas, pragmáticas e discursivofuncionais). Assim, propomos as seguintes estruturas para as construções aqui estudadas, defendendo que houve construcionalização dos itens: 
Figura 4: Representação da construção ainda que

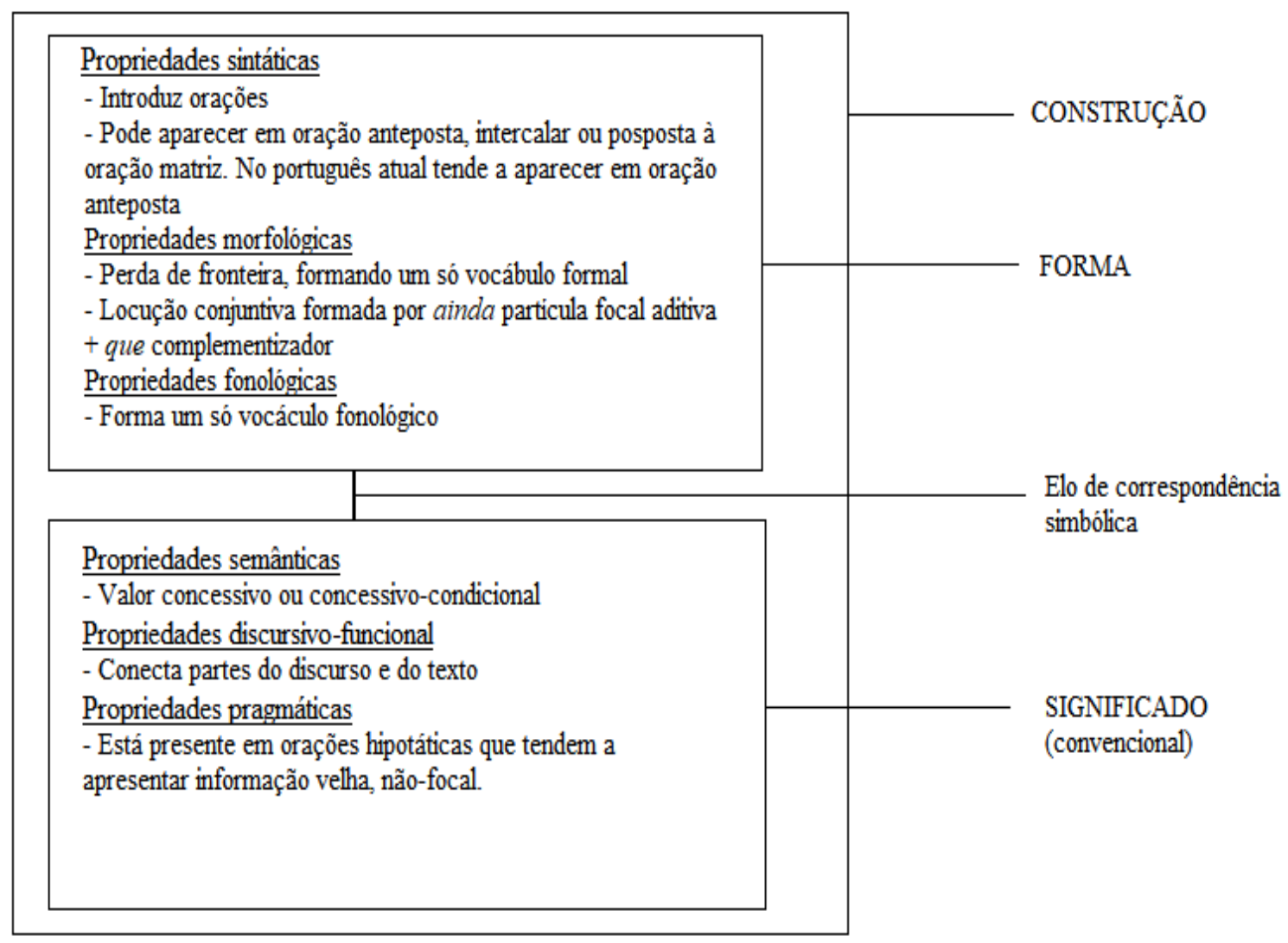

Figura 5: Representação da construção mesmo que

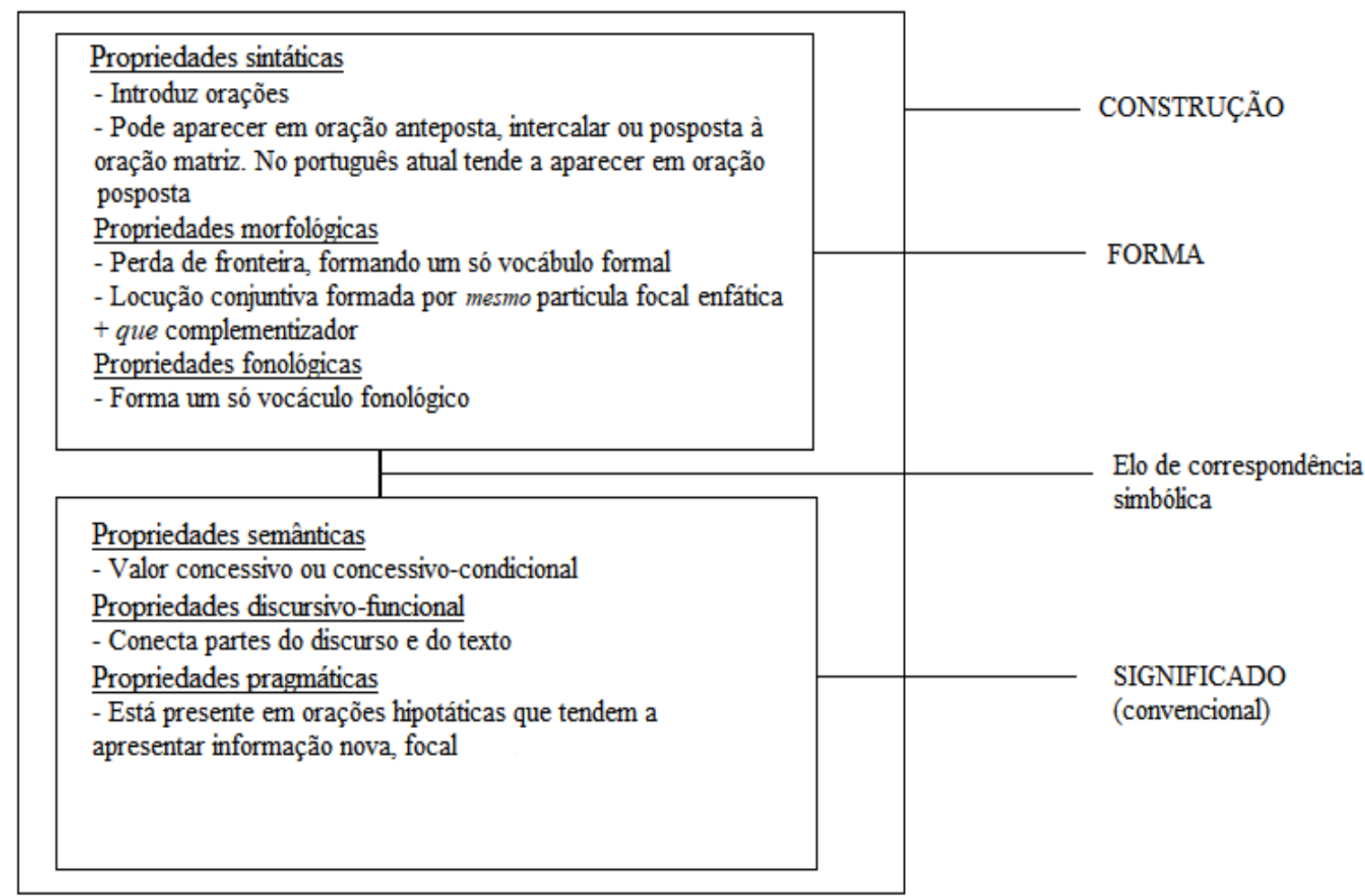

Nas figuras 4 e 5 acima, representamos, de maneira simplificada, como se daria a forma e significado das construções aqui apresentadas, dando conta, de 
forma econômica, das três dimensões da forma e das três dimensões do significado propostas por Croft (2001) para indicar que as mudanças ocorrem de forma independente.

A abordagem construcional baseada no uso propõe que o nosso conhecimento da língua está organizado em rede. Propomos, então, a seguinte rede taxonômica para o esquema [Xque]:

Figura 6: Rede construcional dos conectores no século XVIII

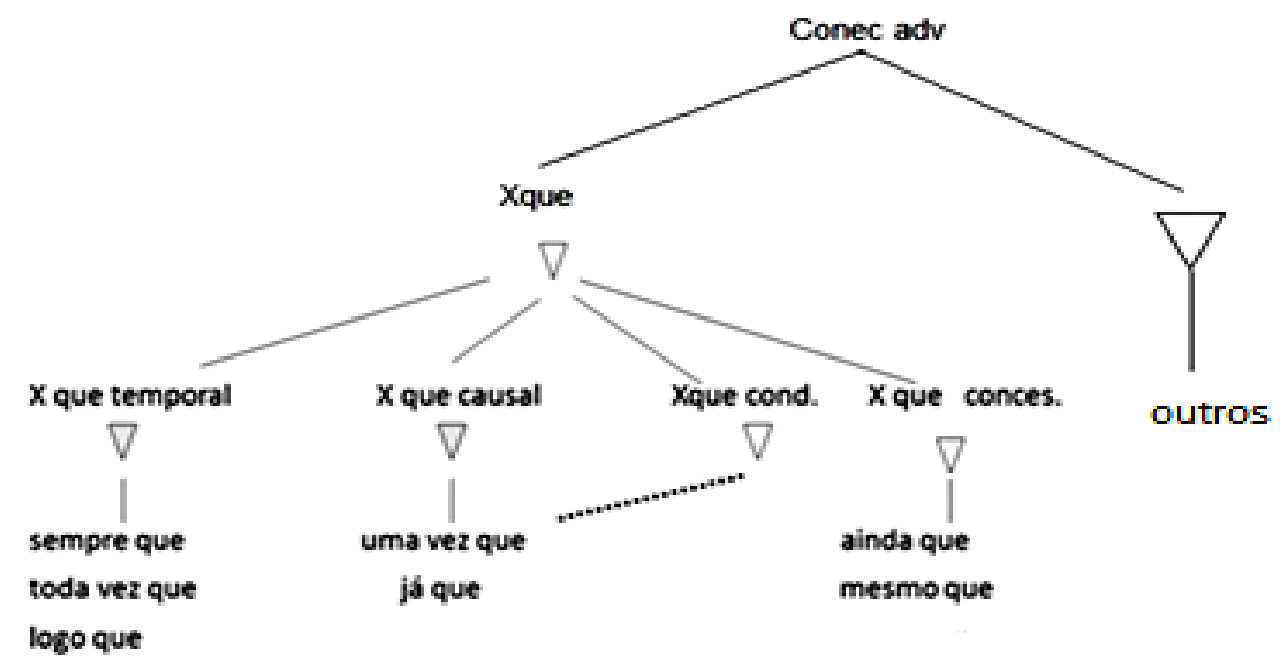

Na figura 6, com a entrada da forma mesmo que na língua, a rede linguística dos conectores contrastivos formado pela forma [Xque] sofreu uma reorganização. Isso porque a partir do século XVIII já foi possível encontrar, no corpus utilizado para a pesquisa, a forma mesmo que com o sentido contrastivo, indicando que, a partir deste século uma nova construção entra no paradigma [Xque] para expressar contraste. Vale destacar que no século XV encontramos contextos ambíguos da forma mesmo que, porém pela baixa quantidade de dados encontrados neste século, preferimos, num primeiro momento, não representá-la na rede linguística deste século.

Ressaltamos que o esquema [Xque] possui relação com outros esquemas existentes na língua portuguesa, como o [Xque]temporal, [Xque]causal etc. (CEZARIO; SANTOS SILVA; SANTOS, 2015).

\section{Considerações finais}


Este artigo teve como objetivo mostrar uma análise histórica da formação dos conectores ainda que e mesmo que em português, assim como demonstrar que, embora tenham valores semânticos semelhantes, elas desempenham papéis pragmáticos e discursivos diferentes.

Entendemos que houve algumas etapas e processos importantes que contribuíram para o surgimento deles na língua. Inicialmente, encontramos dados no qual a forma ainda aparecia várias vezes seguido do que. Nestes casos, ainda era usado como partícula focal aditiva, podendo ser substituído por "também" ou "além disso".

Fatores de ordem discursivo-funcional e pragmáticos também teriam contribuído para o processo de mudança. Os contextos, geralmente, possuíam ideias hipotéticas ou contrastivas, às vezes reforçadas pelo verbo no modo subjuntivo, bem como uma relação de causa ou condição. A literatura mostra que estes domínios semânticos tendem a apresentar grande proximidade em várias línguas.

Assim, seguindo os micropassos de mudança, em algum momento o falante reinterpretou o significado da construção, tendo ainda e que passado a ser vistos como um único bloco cognitivo, pelo processo denominado chunking. Além da metáfora, responsável pela transferência do significado escalar existente em ainda para os significados condicional e concessivo, a metonímia teria sido responsável pela reinterpretação induzida pelo contexto, como mostram estudos de Fontes (2016). Logo, o conector passa pelo processo de construcionalização, visto que houve mudança na forma e na função. Passa ser uma nova construção na língua, ou seja, um novo nó, o que configura uma reestruturação da rede linguística dos conectores em português.

Concebemos que mesmo que tem uma trajetória semelhante. Encontramos, em seus primeiros usos, a ocorrência de mesmo com ideia de partícula focal enfática junto ao que. Os contextos também envolviam o domínio da condição, fator importantes no surgimento do contexto concessivo.

Como sugerido por König (1985a), as concessivo-condicionais teriam sido origem para os usos concessivos de ainda que e mesmo que também em português. As orações com ainda que ainda têm usos concessivo-condicionais, mas tendem a ser usadas como concessivas propriamente ditas; já as orações com mesmo que, 
embora também tenham usos concessivos, tendem a ser usadas como concessivocondicionais, trazendo informação não-factual.

Assim, embora as duas microconstruções estejam relacionadas historicamente, elas têm tendências de usos diferentes, expressando as escolhas do falante/escritor com relação ao que se quer expressar e de acordo com o foco da informação a ser transmitida. Orações com ainda que tendem a aparecer pospostas à oração matriz, expressando informação nova, focal, e as orações com mesmo que tendem a aparecer na posição de tópico, retomando uma informação dada no discurso antecedente.

A embalagem da informação é diferente, porque o contexto pragmático é diferente, o que é mais uma evidência do princípio da não-sinonímia (cf. GIVÓN, 1990; GOLDBERG, 1995), tão caro aos funcionalistas.

\section{Referências}

ANTONIO, J. D. Orações hipotáticas adverbiais e mudança de tópico em narrativas orais e em narrativas escritas do português. Veredas, v. 8, n. 1/2, p. 41-52, 2004.

BYBEE, J. Language, usage and cognition. Cambridge: Cambridge University Press, 2010.

BYBEE, J. Mechanisms of change in grammaticalization: the role of frequency. In: JOSEPH, B. D.; JANDA, R. D. (ed.). The handbook of historical linguistics. Oxford: Blackwell, 2003, p. 336-357.

CEZARIO, M. M.; SANTOS SILVA, T.; SANTOS, M. Formação da construção [Xque]conec no português. Revista e-scrita, v. 6, p. 229-243, 2015.

CROFT, W. Radical Construction grammar: syntactic theory in typological perspective. Oxford: Oxford University Press, 2001.

FELíCIO, C. P. A gramaticalização da conjunção concessiva 'embora'. Dissertação (Mestrado em Estudos Linguísticos). Instituto de Biociências, Letras e Ciências Exatas, Universidade Estadual Paulista, São José do Rio Preto, 2008.

FONTES, M. G. Construções concessivas e concessivo-condicionais com 'ainda que'. Estudos Linguísticos, São Paulo, 45 (1): p.126-141, 2016.

FURTADO DA CUNHA, M. A.; BISPO, E. B.; SILVA, J. R. Linguística funcional centrada no uso. In: CEZARIO, M. M.; FURTADO DA CUNHA, M. A. (orgs.). Linguística centrada no uso - uma homenagem a Mário Martelotta. Rio de Janeiro: Mauad: FAPERJ, 2013, p. 13-39.

GARCIA, T. S. As relações concessivas no português falado sob a perspectiva da Gramática Discursivo-Funcional. Tese (Doutorado em Estudos Linguísticos). Instituto 
de Biociências, Letras e Ciências Exatas, Universidade Estadual Paulista, São José do Rio Preto, 2010.

GIVÓN, T. Syntax: a functional-typological introduction. v. 2. Amsterdam: John Benjamins, 1990.

GONÇALVES, S. C. L.; LIMA-HERNANDES, M. C.; CASSEB-GALVÃO, V. C. (org.). Introdução à gramaticalização: princípios teóricos e aplicação. São Paulo: Parábola Editorial, 2007.

GOLDBERG, A. E. A construction grammar approach to argument structure. Chicago/London: The University of Chicago Press, 1995.

HALLIDAY, M. A. K. An introduction to Functional Grammar. 2. ed. London: Edward Arnold, 1994.

HOPPER, P.; TRAUGOTT, E. Grammaticalization. Cambridge: Cambridge University Press, 1993.

LAMBRECHT, K. Information structure and sentence form: Topic, focus, and the mental representation of discourse referents. Cambridge Studies in Linguistics, 71. Cambridge: Cambridge University Press, 1994.

KÖNIG, E. On the history of concessive connectives in English, diachronic and synchronic evidence. Lingua, Amsterdam, v. 66, n. 1, p. 1-19, 1985a.

KÖNIG, E. Where do concessives come from? On the development of concessive connectives. In: FISIAK, J. (ed.). Historical semantics. Historical Word-formation. New York: Mounton de Gruyter, 1985b, p. 263-282.

NEVES, M. H. M. Gramática de usos do português. São Paulo: EdUnesp, 2000.

ROSÁRIO, Ivo da Costa. A expressão da concessividade em construções do português do Brasil. Tese Doutorado, UFRJ, 2012.

SALGADO, E. As construções concessivas no português brasileiro do século XIX. Dissertação (Mestrado em Filologia e Língua Portuguesa). Programa de PósGraduação em Filologia e Língua Portuguesa, Faculdade de Filosofia, Letras e Ciências Humanas da Universidade de São Paulo, 2007.

SANTOS SILVA, T. A formação de conectores concessivos e concessivocondicionais instanciados pelo esquema [Xque] em português: uma análise construcional de mudança. Dissertação (Mestrado em Linguística). Faculdade de Letras, Universidade Federal do Rio de Janeiro, 2019.

SANTOS, M.; CEZARIO, M. M. Estudo cognitivo-funcional da formação da construção [XQUE]CONECT no Português. Gallæcia. Estudos de lingüística portuguesa e galega. Santiago de Compostela: SPIC, 2017, v. 1, p. 959-974.

TOMASELLO, M. Constructing a Language: a usage-based theory of language acquisition. Cambridge: Cambridge University Press, 2003. 
TRAUGOTT, E. C. Subjectification in grammaticalisation. In: DIETER, S.; WRIGHT, S. (eds.). Subjectivity and subjectivization: linguistic perspectives. Cambridge: Cambridge University Press, 1995, p. 31-54.

TRAUGOTT, E. C.; TROUSDALE, G. Constructionalization and Constructional Change. Oxford University Press: Oxford, 2013. 